\title{
Applying Critical Discourse Analysis in Translation of Political Speeches and Interviews
}

\author{
Mehdi Mahdiyan \\ Department of English, Quchan Branch, \\ Islamic Azad University, Quchan, Iran \\ Muhammad Rahbar \\ Department of English, Quchan Branch, \\ Islamic Azad University, Quchan, Iran

\section{Dr. Seyed Mohammad Hosseini-Maasoum} \\ Department of Linguistics \& Foreign Languages, \\ Payame Noor University, I.R. Iran \\ Email:hosseinimasum@yahoo.com
}

Doi:10.5901/ajis/2013.v2n1p35

\begin{abstract}
From the ancient times, language has been using as an ingenious device for transmission of ideology and for manipulation of the audience minds by those who have been in power. As Kress in Van Dijk (1985: 29) states, "Ideologies find their clearest articulation in language. Hence, a powerful way of examining ideological structure is through the examination of language". Adopting Critical Discourse Analysis with particular emphasis on the framework of Fairclough (I989) and utilizing the notions of SFL by Holliday (1985), the present investigation is an attempt to shed light on the relationship between language and ideology involved in translation in general, and more specifically, to uncover the underlying ideological assumptions invisible in the texts, both source text (ST) and target text (TT), and consequently ascertain whether or not translators' ideologies are imposed in their translations. The corpus consisted of President Bush speeches during the years 2005 till 2008 about the nuclear program of Iran. The data consist of ST (in English) in the form of a political interviews and TTs in the form of 8 translations in Persian. The obtained results proved the fact that the application of CDA for the analysis of the ST and TT helps the translator to become aware of the genre conventions, social and situational context of the ST and TT, and outlines the formation of power and ideological relations on the text-linguistic level.
\end{abstract}

Key words: CDA, Translation Studies, power relations, ideology.

\section{Introduction}

The issue of genre and text type has been the topic of hot debates in the field of translation. Every genre has its own conventions and approach, which distinguishes it from the other text types; therefore, only the matter of word choice and structure cannot be determining factors in the act of translation. Various text types require different techniques and strategies for translation in order to be efficient in conveying the intended message of the source text into the target text. Another important matter is the inter relatedness of the texts and the social circumstance in which they are produced. Every text will be organized according to some concepts, beliefs and ideologies of a group, community, party or a nation. 
This issue makes the translation from a source to a target trickier because the selected words, their arrangement, the structure in which they appear are not chosen haphazardly and there would be some dominant thought according to which these texts are written.

Amongst different genres, political texts may appear more challenging for translation. At first, they may seem as like the other text types but the ideas behind the word choice; structure and message of these texts are complicated and subtle. Ideologies, attitudes, and feelings are expressed through language (written or spoken) and by analyzing speeches we can figure out the speaker's thoughts and emotions about or towards an event or phenomenon. The investigation into politicians' remarks and comments becomes more essential when we find out that their ideologies and intentions are not always stated clearly and explicitly. As Van Dijk (1993:29) contends, the text (written or spoken) is like "an iceberg of information," and it is only the "tip" which is really expressed in words and sentences. Therefore, he concludes that the analysis of the implicitness is very helpful in the study of the underlying ideologies.

Here a fairly new branch of linguistics, which is called Critical Discourse Analysis, comes in handy to level the problem of ignoring the hidden ideologies behind a text and tries to disclose them and show the certain features away from the canon of laypeople. Because of the complexity of the discourse in terms of both structure and meanings, the understanding of text does not just come from the analysis of vocabulary, grammatical features or cohesive devices. For gaining a thorough understanding, the worldview that the author and the receptor bring to the text and both situational and inter-textual must be considered. CDA provides this opportunity to adopt a social perspective and critical thinking into investigation.

Therefore, this is the main objective of Critical Discourse Analysis (CDA) to discover and shed light on the hidden part of discourse. In political discourse, words are at the service of transferring the power or ideologies of one group or nation to the other. As a consequence of globalization, political texts may be required to be translated to the other languages. Here, the task of the translator is not just rendering the linguistics features of the source text, but $\mathrm{s} /$ he should be aware of the underlying theories and ideologies which scaffold a political text and in some cases try to add, delete of clarify the text in order to make it comprehensible for the target text audience. Translation, although often invisible in the field of politics, is actually an integral part of political activity. (Bassnett\&schaffner, 2010:22). Translation is in fact part of the development of discourse, and a bridge between various discourses. It is through translation that information is made available to addressees beyond national borders; and it is very frequently the case that reactions in one country to statements that were made in another country are actually reactions to the information as it was provided in translation (schaffner, 2004:I I8).

The advent of Critical Discourse Analysis (CDA) has influenced not only the branch of applied linguistics, but it has also affected Translation Studies and found its way in it. CDA sees language in a dialectic relationship with social reality, i.e. a communicative act (act of translation or interpretation) is affected by social reality and is used to sustain or change the social reality. In some cases, the orator wants to conceal a reality, in some other s/he may want to magnify it and in some others wants to show it reversely. According to CDA, the usage of text-linguistic elements reflects the text producer's aims and affiliation to a special ideology, which, in its turn, may establish unequal power relations (class struggle, ideological struggle) between the participants of the communicative event. Hence, the salient aim of CDA within TS is to reveal the underlying and often implicit ideological and power relations in spoken and written discourse. Because CDA is brand new approach, it cannot be considered as a fixed theory but rather a cluster of approaches that have been started by the earlier research in functionalist and discourse analysis theories within TS.

The mixture of CDA into TS has made to look at the concept of translation from a different angle. While the source text is produced in some specific socio-cultural situation in accordance with the norms and values of that society or organization, the translator's socio-cultural background, linguistic 
background and experience with other texts and discourses directly affect the final product of the act of translation in target text. This may result in the fact that either translator embeds their own worldviews and ideologies in translations unconsciously or deliberately according to their own assumptions or the requirements stated in the translation brief.

\section{The Nature of Translation and Text Analysis}

The term translation can be misleading by nature. Discrepancies can be obviously seen in viewpoints aired by different scholars regarding the definition of this key term. Munday (200I:4) argues that the concept of translation may refer to several things. First of all, it can refer to the field of translation in general, it can refer to the product, i.e. a translation of a text, and it can refer to the process of translating. The process of translating involves a translator who changes the language of an original ST into another language of a TT, i.e. changing the language code. From a different viewpoint, Schjoldager (2008: I8) regards a text as a translation involves basing it on these three postulates which the third one is as follows: there is the relationship postulate: "It is assumed that the source and target texts share certain features that can be ascertained in a comparison between the two." This claim maybe generally true, but regarding translation of political discourse, it can be somehow simplistic. It does not take into consideration the ideological, social, political, and economical differences between the society in which a text was produced by a writer and the one a translator takes the text and translates it.

Translation Studies, which is by definition a multilingual research field, has developed from a profession and a craft into an interdisciplinary field influenced by various branches of linguistics, comparative literature, communication studies, philosophy and a range of types of cultural studies, including post colonialism and postmodernism, as well as sociology and historiography (Munday 2008). Researchers from different theoretical backgrounds contributed to the development of the field with approaches that tended to shape the study of translation according to those diverse backgrounds.

Through its long history in different parts of the world, translation practice and study have been dominated by the debate over the degree of translation's equivalence, and degree of faithfulness. Dichotomies, such as 'word-for-word' versus 'sense-for-sense' or 'literal' versus 'free' translations have surfaced in many professional and academic circles (for a review, see Munday 2008: 19-22). Such debates concerning translation theory have traditionally focused mainly on the comparison of source text (ST) and target text (TT), taking the concept of 'fidelity' as the basic criterion. Translation Studies today is no longer concerned with examining whether a translation has been 'faithful' to a source text. Instead, the focus is on social, cultural, and communicative practices, on the cultural and ideological significance of translating and of translations, on the external politics of translation, on the relationship between translation behavior and socio-cultural factors. In other words, there is a general recognition of the complexity of the phenomenon of translation, an increased concentration on social causation and human agency, and a focus on effects rather than on internal structures. As cited in Bassnett\&schaffner( 2010:12).

\section{Translation Studies and Critical Discourse Analysis}

The integration of discourse analysis in translation studies (TS) was initiated in the functionalist theories of translation (Munday 200I:73) which, including text analysis of the ST, aimed at the analysis of text type, language function, the effect of the translation and the participants of the translation event. The discourse analysis approach to TS applied Michael Halliday's register analysis model, which was mainly used to analyze the pragmatic functions of linguistic elements in both ST and TT, e.g. the first theoretical frameworks were proposed by Mona Baker and Julian House (ibid. 90). Halliday considers 
language use as a communicative event and describes three strands of functional meaning as ideational, interpersonal and textual meaning. Interpersonal meaning refers to use of language in order to establish a relationship between text producer and text receiver. Power is one of the rudimentary types of relationship in the analysis of interpersonal meaning. The schemes of choices made by translator from the array of the lexico-grammatical resources of language can establish the interpersonal meaning. Then notions like context, functions, culture, textuality, style, genre, and discourse which are studied in pragmatics, discourse analysis, cultural studies, and communication studies had an effect on Translation Studies.

CDA is mainly used to analyze the text linguistic factors of one language and one culture. However, in translation studies this approach should be applied to both primary ST and secondary TT. CDA sees translation as a social, cultural, and political act and tries to combine these three factors to analyze both ST and TT. Most of the research which has been done within TS using CDA focuses on translation as a social action, answering questions such as: who is translating for whom, what is being translated, when is it being translated and what are the effects on the receiving culture (Chilton cited in Schäffner 2002:60). According to Valdeón, In translation studies, CDA has an optional role and is mainly used as an auxiliary tool to the existing methodological approaches to provide a comprehensive reflection on language and culture (2007:100). CDA may become a useful means in the decision making of the translation strategy, the ST, and the TT context, cultural and social differences between source and target language communities. It also helps to know the cognitive process of translation and the contribution of the translator in the interpretation (understanding) of the source text meaning which has not been clearly described in TS.

Christina Schäffner (2004:136) states that it is the human communicative activity in the sociocultural settings which is common in both CDA and TS, and that texts and discourses are the product of this activity. Therefore, here the translator is not just a kind of mediator who renders one language into another, but, on the contrary, s/he produces new discourse in the TL. Unlike discourse analysts, translators create a new act of communication on a previously existing one in a new target language environment by using their own background knowledge (linguistic, social and cultural) and negotiating the meaning between the ST producer and the TT reader (Hatim\& Mason 1990:2). Translations are perceived as target texts in a new socio-cultural context, which are based on a source text which functioned in its original socio-cultural context (Schäffner 2004:I38). Accordingly, the CDA applied to TS revolves around the role of translator in translation process on the basis of translation strategy taken by the translator and the design of target audience. Christina Schäffner (2004:17) focuses on both the purpose of the translation and audience design from two angles, i.e. target audience with more or less the same knowledge of the ST subject and target audience which lacks knowledge about the ST issues. Hence, it is possible to state two main purposes in the translation:

a) the translator must convey information with certain changes in the TT

(According to Valdéon (2007: 102) omissions, additions, permutations and substitutions may be included in the vocabulary of CDA as well, since they are connected to the editing and production processes of STs and TTs) (Dynamic approach).

b) the translator conveys information in the TT with no significant changes according to wordfor-word translation strategy (static approach).

To put it in a nutshell, in TS, CDA is applied to both the ST and the TT, which are taken as the products of text production, i.e. the ST producer's motivated choices in the ST language and culture and the translator's motivated choices for the production of a new TT in a new language and culture. There are two probable translation strategies on the basis of the text type and purpose of the translation: dynamic or static translation strategy. 


\section{Translation and Political Discourse}

The objective of a political discourse analysis, which adopts critical goals, is to denaturalize ideologies. Denaturalization involves showing how social structures determine properties of discourse and how discourse determines social structures (Fairclough, 1995). According to Fairclough (1989), CDA aims at systematically exploring how these non-transparent relationships are factors in securing power and hegemony and it draws attention to power imbalances, social inequities, non-democratic practices, and other injustices in hopes of spurring people to correction actions. A critical discourse analyst should be able to differentiate ideology from knowledge so the concept of discourse is essential for a scientific understanding of discourse (Van Dijk, 200I). Discourses always involve power and ideologies, and because translators have different backgrounds, knowledge, and power positions, they can be interpreted differently by them. Therefore, we do not have the "right" interpretation whereas a more or less plausible or adequate interpretation is likely (Fairclough, 2002; Wodak \& Ludwig, 1999) (cited in Nahrkhalaji, 2006:6).

As translation studies can be considered as a brand new field of study, the relationship between it and political discourse has not been scrutinized. Some researches have been done to analyze this relationship applying different approaches such as textual analysis of Anna Trosborg (1997;2002) and more frequently political discourse analysis or critical discourse analysis whose leading features can be Christina Schaffner and Hatim and Mason (Christina Schäffner 1997; 2002; 2003; 2004; Hatim and Mason 1990; 1997). A factor which received most of emphasis was considering this fact that when analyzing political discourse, the surrounding societal and ideological context in which the text is produced should be taken into consideration (Schäffner 1997:I19). The recent researches have considered the role of translators as mediators who on the basis of the knowledge they have from the source text and socio-cultural and political situations interpret the texts and try to adjust them with the norms, beliefs and ideological considerations of the target society. The translator interprets the ST according to his/her cultural, social and political background which may be ideologically shaped. Hence, the analysis of the ST and the TT often deals with foregrounding the connections between linguistic, translational, and ideological components in political texts (Valdeón 2007:100).

Political discourse is often of relevance not only for the specific culture of the text producer, but may be intended for a wider audience as well (Schäffner 2004:I17). Due to globalization, politics have become internationalized, and it is through translation information is made available to addressees beyond national borders (ibid. I20). Currently translation studies is an essential developing factor of political discourse. Among the translation studies scholars, Christina Schäffner has done valuable researches to show the relatedness of translation and political discourse (1997; 2002, 2003; 2004). She has tried to concentrate on cultural, social and political aspects of translation and text production in the source and target cultures and apply discourse analysis to translation. It can be said that her research deals principally with translation strategies, which are used to transfer a culture-bound source text into another target language community with a limited knowledge to the foreign culture. According to Schäffner (ibid. 127), political texts usually reflect culture-specific conditions of their production. Their translations inform a target audience about a communicative act that had already been fulfilled in the ST community. In this condition, the ST can both be addressed to a single or multiple TT communities. On the basis of this fact that translation is a mediating intercultural activity, lots of factors may affect the translation into TT such as the audience, situation, function of the text in TL community and text type which are not of equal importance in ST. The functions of the ST and TT in their respective cultures determine the translation strategies, e.g. if the function of the ST was to persuade the source language (SL) audience, then the function of the target text in the TL culture will have only an informative function (ibid. I28). This point of view states that the TL audience does not have the same 
knowledge as the SL audience and therefore the obligatory alternations have to be made in the TT by the translator. In other words, this perspective sees the ST as not having the same force and effect on the TT audience in comparison to ST audience.

\section{Translation, Ideology, and Power}

Moving away from those debates that focused on translation equivalence at the sentence level, or even sometimes at the word level, a new approach looked at translation using a larger textual approach, i.e. discourse and register analysis approaches, influenced by and benefiting from the growth of discourse analysis in applied linguistics. Building on Halliday's systemic functional grammar (Munday 2008: 90), these approaches study translation as a process and product, focusing on register and discourse level (see, for instance, Hatim and Mason 1990, Mason 2009). However, earlier studies in this branch of research focused mainly on the formal definition of discourse. There was little attention paid to the wider effects of discourse that go beyond the linguistic content to consider the social, political and economic implications of discourse in translation.

Acknowledging that ideology has always functioned as an 'invisible hand' in translation practice, and the fact there are factors which influence translation, not only of a linguistic nature, but also representing the transmission of ideology between different nations and countries, a cultural and ideological movement flourished in the field of translation studies that was represented in the approach towards the analysis of translation from a cultural studies angle (Munday 2008: I25).

According to van Dijk (1997, 200I), ideology is articulated in discourse. Therefore, translation can also articulate, that is produce and reproduce, ideology. Ideologies are individual convictions, and as a result, different translators sharing diverse ideologies can translate political texts differently. It is possible that translators who support opposing political parties will translate political discourse differently and will exhibit different attitudes to the ideologies expressed by the source text. Therefore, different translations can reflect differences in ideologies, which can potentially surface as differences in superstructure. Translators as members of a society do not live in a vacuum. They are inevitably affected by the rules, values, and beliefs of their native country. Consequently, translating a text, they comprehend it, try to filter it, adjust the text to the accepted norms of their society and then produce a new form of the ST which would have higher degree of acceptability from the perspective of readers.

In international context, translation may play a prominent role in and be a vital vehicle and means of communication in publishing and publicizing political agendas as well as in maintaining political power (Banhegy, 2009:5). In this respect, translation itself may easily become a political tool. Translation therefore can serve purpose of gaining, maintaining, and even abusing political power in the interests of certain political groups.

Patrons can encourage the publication of translations they consider acceptable and they can also quite effectively prevent the publication of translations they do not consider so (Lefevere, 1992:20). Similarly Munday commented on the role of ideology and power in translation: A key question is what kind of link there is between the lexical/syntactic choices and the ideological context. For Halliday (1978), as for critical discourse analysts such as Fairclough (e.g. 200I), it is the sociocultural context or location of power which to a large extent determines the lexicogrammatical choices (2008:3).

\section{Theoretical Framework of the study}

The approach to CDA chosen for this study is that of Norman Fairclough (1995, 2000, 2003). For Fairclough, in contrast to the social psychological approach of Wetherell and Potter (1992), the socialcognitive model of van Dijk (1993, I998, 200I) and the discourse-historic method of the Vienna 
School (Reisigl and Wodak, 200I; Wodak, 1996,2002; Wodak et al., I999), CDA means the analysis of relationships between concrete language use and the wider social cultural structures. [... ] He attributes three dimensions to every discursive event. It is simultaneously text, discursive practice - which also includes the production and interpretation of texts - and social practice. The analysis is conducted according to these three dimensions. (Titscher et al,, 2000: 149-150)

Besides, Hallidayan model meets the goals of the present study. Therefore, this study is conducted within this framework as well as Fairclough's one. At first, the researcher begins analyzing U.S. President's linguistic choices in his comments on Iranian nuclear program. The analysis is carried out within the three functions or meanings of Hallidayan model of language (ideational meaning, interpersonal meaning and textual meaning).

\section{- Active and passive voices}

- Nominalization

- Modality

- Thematization

- Emotive language (emotive lexical choices)

Then, following the Fairclough's model, interpretation and explanation of the discourse come next.

\section{Materials and Procedure}

In order to conduct this analysis, a wide array of Bush's comments regarding Iran's nuclear issue is collected. These remarks and comments are taken from Bush's addresses and press conferences. The relevant data have been downloaded from the White House website at www.whitehouse.org. To make the investigation feasible, the researcher has to base this analysis on a sample of comments. Thus, he has decided to focus on 20 excerpts of Bush's comments randomly selected from 20 of his political speeches and press conferences concerning Iran's nuclear program from 2005 to 2008.

Having analyzed the selected parts according to the mentioned factors, the social and situational context of the speeches will also be analyzed. The next step is the analysis of translation of those parts in Persian produced by a group of eight translators all having M.A. in translation studies on the basis of the same factors applied to the source text. The data will be shown comparatively and the areas of similarity and difference between the ST and TTs will be identified to understand in which categories the translator deviated from the dominant ideology of the ST. Therefore, the researcher selected mixed method design for this study. The qualitative part includes the analysis of ST and TT and the quantitative part comprises the data analysis, categorization of analyzing factors, and finally showing their percentage.

\section{Results}

\section{I. The Analysis of Active and Passive Voice in ST and TTS}

The comparison of passive and active voices in the source and the eight target texts did not provide considerable results from ideological point of view. As discussed in the analysis of the ST, the speaker intentionally used either active or passive voice to attribute good deeds and actions to the U.S. and its allies and to condemn Iran to threatening actions against the world. However, in the translations obtained from the translators, there is not a big change in this area and they mostly preferred to pursuit 
the same ideology as that of the speaker. Here some examples are displayed the areas the TT deviates from the ST:

\section{Passive $\rightarrow$ Active}

ST: So I think there's universal agreement that we don't want them to have a weapon. And there is agreement that they should not be allowed to learn how to make a weapon. And beyond that, I think that's all I'm going to say. (December I9, 2005)

$$
\begin{aligned}
& \text { [:]:TTI }
\end{aligned}
$$

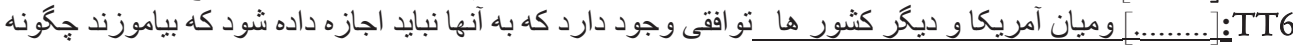

$$
\begin{aligned}
& \text { سلاح بسازند. }
\end{aligned}
$$

ST: You see, a non-transparent society that is the world's premier state sponsor of terror cannot be allowed to possess the world's most dangerous weapons. So, as we confront Iran's nuclear weapons ambitions, we're also reaching out to the Iranian people to support their desire to be free; to build a free, democratic, and transparent society.

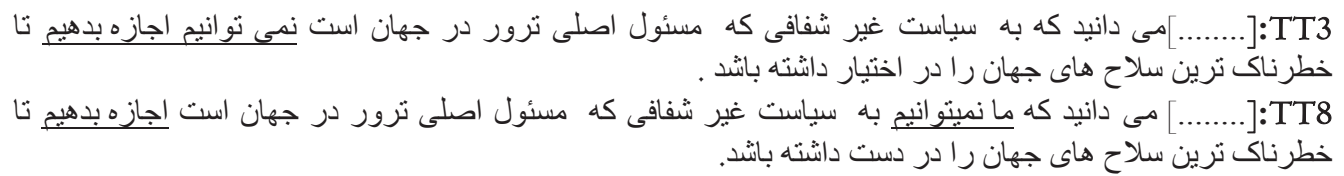

In English and Persian linguistic structures, the choices about the representation of actions, actors and events have to do with the distinction between active and passive voices. Example (I) shows the possible ways in which a Negative action can be syntactically expressed in different ways. In TT6 the responsible agent of the action "not allowing" has been made explicit while in TTI it has been left unclear and unknown as it was in ST.

As mentioned there was not a significant change from passive to active voice, here some examples show the reverse form, which is from active to passive voice:

\section{Active $\rightarrow$ Passive}

ST: And secondly, We will continue to stay engaged in helping reformers, in working to advance liberty, to defeat an ideology that doesn't believe in freedom. (August 2I, 2006)

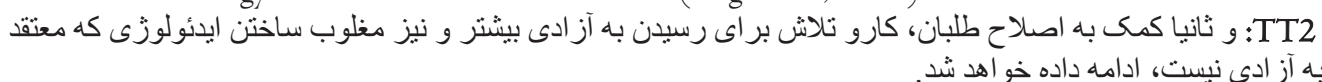

ST: The first goal of any dialogue with a partner with whom we're trying to create peace is to have a common objective, a stated goal.

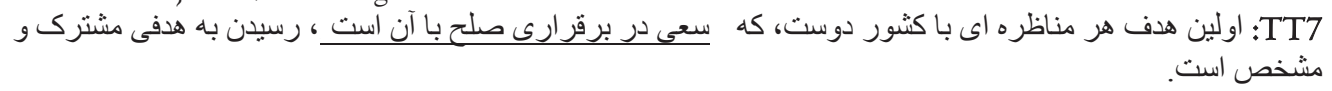

\subsection{Nominalization}

The second item to be discussed is nominalization. As stated earlier, nominalization is used to delete information from a sentence. Through this process, features of the sentence such as action, participants, indication of time and modality may be deleted.

Nominalization $\rightarrow$ verb 
ST: It reminds the nations of the world that there is an ongoing diplomatic effort to convince the Iranians to give up their nuclear weapons ambitions.

$$
\begin{aligned}
& \text { ترك5 اين مسئله به تمامى ملل جهان يادآور مى شود كه تلاش دييلماتيك مداومى جهت متقاعد ساختن اير انبان مبنى بر }
\end{aligned}
$$

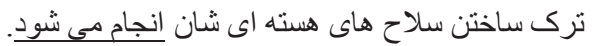

ST: So I think there's universal agreement that we don't want them to have a weapon.

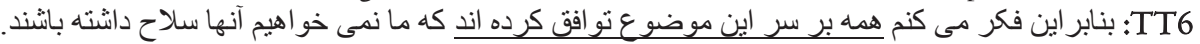

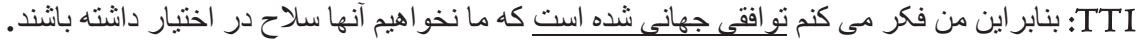

Syntactically, verbs tend to convey concrete notions, actions or processes rather than less effective abstract concepts. Although there is only a tendency, but it is quite enough to change readers' first interpretation out of the same issue. These examples are one type of nominalization, which is altered into a verbal version of the action in TTI to change readers' vision towards a more narrowed and specific event. On the other hand, in TT2, the ST sentence was translated in such a way that, nobody can ever make any guess about the actual involvement of an actor.

\subsection{Modalization}

As explained earlier, modality refers to a speaker's attitude towards, or opinion about the truth of a proposition expressed by a clause. It also extends to his/her attitude towards the situation or event described by a clause (Halliday, I985). Modality has to do with the judgment of the speaker of the probability, casualty, obligation, or inclination involved in what he is saying. It represents the speaker's angle, either on the validity of the assertion or on the rights and wrongs of the proposal.

ST: ... the world is united and concerned about their desire to have not only a nuclear weapon, but the capacity to make a nuclear weapon or the knowledge to make a nuclear weapon, ...

In this extract from the president Bush speech, non-modalized language used to show Iran is definitely after producing nuclear weapons, however, it had some different rendering in Persian:

TS5 . كثور هاى جهان در مورد آرزوى احتمالى آنها در جهت نه تنها دار ا بودن سلاح هسته اي بلكه ظرفيت ساختن

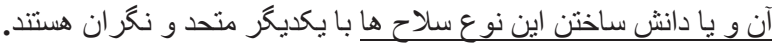


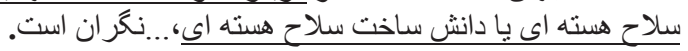

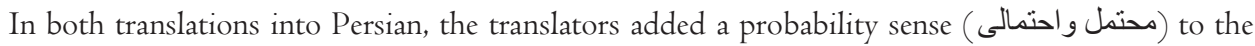
president's speech to show their country is not desirable to have nuclear weapons and it can be his inference and it is not a definite fact.

ST: My message to the Iranian people is you can do better than to have somebody try to rewrite history. And you can do better than having somebody who's trying to develop a nuclear weapon that ...

like the previous example, here Bush used a non-modalized language to show his certainty about the acts of Iranian president for developing nuclear weapons that has different renditions in Persian in which degrees of uncertainty and inference are included.

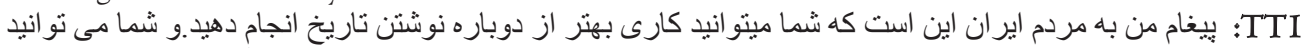

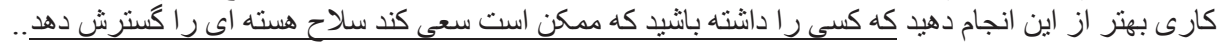

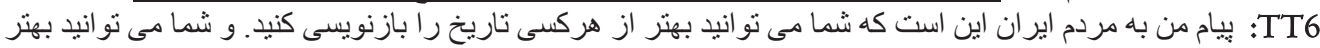

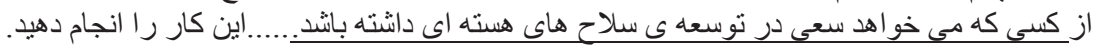

In TTI, the translator by adding a modal (مهكن است (مهت ) tried to lessen the negative load of the bush speech, which directly addresses the president of Iran and tried to state that Bush's speech just can be a possibility. In TT6, the other translator by changing the tense of the sentence to future (مى خواهد), attempted to prove that this can be a guess about the future and it may not realize as stated by Bush.

ST: ...that for the sake of world peace they should abandon their nuclear weapons ambitions. 


$$
\begin{aligned}
& \text { TT5: و اينكه به خاطر صلح جهانى انتظار مى رود آنها خو استه ها سى سلاح هسته ايثان را كنار بكذارند. }
\end{aligned}
$$

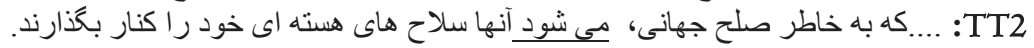

As it is clear from the ST, the speaker intentionally used a modal of obligation (should) to show Iran is forced to stop its nuclear program for making nuclear weapons. However, in TT5, the translator changed one function of should which is obligation with the other one which is for expectation ( انتظار to alleviate the forceful load of the ST. In TT2 on the other hand, the translator replaced the forceful power of should and added a sense of possibility and advisability (مى شود).

\subsection{Thematization}

Placement of information within a sentence and their order, i.e. which one comes first and which last can directly change the message of the sentence and affects the listener or the reader comprehension or as mentioned before, What the speaker or writer puts first will influence the interpretation of everything that follows. In this part some examples from the ST are chosen in which the translators deviated from the original form and changed the order of information in the sentence.

ST: By supporting democratic change in Iran, we will hasten the day when the people of Iran can determine their own future and be free to choose...

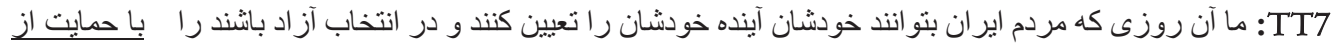

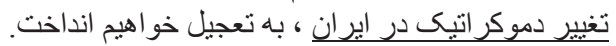

In the above extract, by supporting democratic change in Iran is suggesting this view that Iran's internal affairs are in a state of chaos and the Iranian nation is not enjoying enough freedom and on the whole, the country and the people are in urgent need of others' help. The listeners may also have this sense that U.S. is concerned about the democracy and freedom in Iran. This linguistic manipulation diverts the people's attention from the real motives of America in this standoff. However, in the translation submitted, the translator changed the place of the theme whether intentionally or accidentally and thereby the idea which induced in source text reader may not be transferred to the target text reader.

ST: The path chosen by Iran's new leaders -- threats, concealment, and breaking international agreements and IAEA seals -- will not succeed and will not be tolerated by the international community. بإئ جو امع بين المللى روش نا موفقى كه توسط رهبر ان جديد اير ان انتخاب شده است يعنى تهديد، ينهان كارى و زير

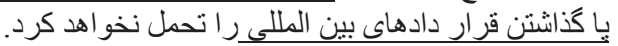

In the above extract, to convince the public opinion that Iran's actions are not in compliance with international agreements and describe Iran as the violator of universal regulations, George W. Bush has placed such issues like: The path chosen by Iran's new leaders -- threats, concealment, and breaking international agreements and IAEA seals, and so forth as the themes of his remarks and this topicalization helps the listeners to view the issue from this perspective that Iran has no respect for international agreements and regulations and this makes the public mind point the finger of blame at Iran. As it can be seen from the Persian rendition of this part, the translator changed the place of international community to the beginning of the sentence and this may lead to another interpretation.

\subsection{Emotive Language or Lexicalization}

The vocabulary type chosen by a speaker or writer affects the minds and the attitudes of the readers and the listeners differently. The types of words that a writer uses can activate particular presuppositions, reveal speaker's attitudes, require reader agreement for interpretation, and so forth.

ST: The Iranian regime sponsors terrorists and is actively working to expand its influence in the region.

$$
\text { TT8 حكومت اير ان تروريست ها را حمايت مى كند و فعالانه تلاش مى كند تا تاثيرش را در منطقه افز ايش دهد. }
$$


Tو7 دولت اير ان از تروريست ها حمايت كرده و در جهت توسعه ت تاثير خود در منطقه فعالانه كار مى كند.

As pointed in the analysis of the source text of this part, name-calling is a prevalent strategy used by politicians applying derogatory terms that dehumanize the enemy. Simply put it, they use terms that evoke fear, anger and hatred; and it distances the audience, making it easier to accept a course of action towards the enemy. Bush has used the word 'regime' 30 times in comparison to the positive synonym 'government' whose number is 3 . This is going to show that Iran's government and their authorities are not legal as the word regime suggests such a meaning into the public mind. On the contrary, two translators preferred not to use this offensive term and replace it with other words meaning government

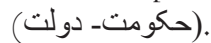

In the table below, the overall percentages of different categories according to which the analysis of ST and eight TTs was done is displayed. It can clearly show the translators may or may not follow the ideology and strategy of the ST speaker and they changed it both intentionally or according to their own ideology and haphazardly or unintentionally. Although it is noteworthy in some items such as thematization and active/passive structures, the choices of translators were approximately the same as those of the ST speaker.

Table I: the overall percentages of different discursive structure in ST and TTs

\begin{tabular}{|r||l||c||c||c||c||c||c||c||c||c|}
\hline No & $\begin{array}{l}\text { Discursive } \\
\text { structure }\end{array}$ & ST & TTI & TT2 & TT3 & TT4 & TT5 & TT6 & TT7 & TT8 \\
\hline \hline I & Passive sentences & 22.3 & 24.1 & 23.4 & 22.9 & 21.3 & 21.8 & 22 & 22.2 & 23.1 \\
\hline \hline 2 & Active sentences & $4 \mathrm{I} .7$ & 40.5 & 41.9 & 4 I.I & 43 & 42.9 & 42.5 & 41.4 & 4 I.2 \\
\hline \hline 3 & Modalization & 4.7 & 5 & 4.2 & 5.4 & 3.9 & 5.1 & 4.8 & 4.4 & 5.3 \\
\hline \hline 4 & Thematization & 25.3 & 25.4 & 24.7 & 25.9 & 25.6 & 23 & 24.4 & 26 & 23.9 \\
\hline \hline 5 & Nominalization & 29 & 27.7 & 30.2 & 28.4 & 28.7 & 29.3 & 30.6 & 29 & 28.2 \\
\hline \hline 6 & Lexicalization & $27.6 \mathrm{I}$ & 25.6 & 25.9 & 26.3 & 27.1 & 28.4 & 28.7 & 27.3 & 27.7 \\
\hline
\end{tabular}

The aforementioned TT analysis exposed a number of complications related to the translation of political texts. Even though the text type required a dynamic translation, most of the translators have used the static strategy to translation and have applied a very literal approach. Hence, most of the translations reflect the SL structure, which delays the level of perception of the TT. It may be related to the phenomenon of "foreignizing", i.e. the usage of borrowing from the English language and grammatical structures, but may also be related to the lack of time and accurateness during the contentment of the translation task. There are a great number of linguistic and grammatical inaccuracies in the translations, which denote the fact that the translators have not been able to get fully acquainted with the translation brief and the situational and social contexts of the ST and TTs. Thus, the trustworthiness of the translation suffers. According to Hatim and Mason (1997:176), the texture and structure are at risk when the context is misinterpreted. It seems that most of the translators have been able to understand the ideological and power struggle between the two participants, but have not been able to determine what textual means are used to create the respective power struggle in the ST and have not been able to transfer the same effect in the TL. There are, however, a number of very good solutions where translators have applied translation strategies to explain or substitute a SL term with a more natural equivalent term in the TL in order to make the TT more accessible to the target reader.

Both the ST and TT analysis offers a very short insight into the problems and solutions present in the TTs, but it is a good basis for further research in the particular field of the CDA framework within TS. The translation quality has hurt not only due to the fact that the translations were done on a 
voluntary basis, but also to the fact that the translators did not have a ready-made framework at hand, which would provide them with tools for the analysis of the ST and definite guidelines which are necessary in the translation of culture-bound political texts. Most of the translators failed to pay attention to the situational and social contexts, background information, linguistic choices, semantic and pragmatic relations in the text and thus created literal translations causing some misunderstandings in the TL. These findings demonstrate the fact that the translation brief alone is not enough to provide the translators with the valuable information regarding the underlying power and ideological struggles in political texts and thus leads to the conclusion that CDA framework may become a useful tool, which would help the translators to perform a critical analysis of the ST at the initial stage of the translation process. Additionally, the application of the CDA framework in translator training would provide the future translators with an analytic tool which helps them to found a step-by-step procedure for the analysis of the ST and the production of the TT, which would advance their awareness of the importance of the role of language in the socio-cultural context as well as the impact of their own textual choices in the translation process.

\section{Conclusion}

The main aim of this thesis was to prove the hypothesis that CDA is a helpful implement in the translation process of political texts. The CDA integration in translation is a very new field within TS and has not been researched comprehensively. The existing research - contains a variety of approaches and reflections and does not offer an applicable model for translation-oriented analysis of both STs and TTs within political discourse. Thus, this thesis deals with the integration of Norman Fairclough's CDA model mixed to Michael Hallidy's SFL into the translation process of political texts, i.e. in this thesis the materials for the analysis were both some political interviews and some political speeches. The integration of the CDA model in the translation process was based on the earlier considerations within TS by such CDA/TS scholars as Basil Hatim and Ian Mason (I990; 1997), Christina Schäffner (1997; 2002; 2003; 2004), Robert S. Valdeón (2007), etc. The framework created in this thesis may be considered as an optional supplementary tool or a set of guidelines for the ST and TT analysis during the process of translation of highly culture-bound political texts which display significant power and ideological struggle between the interlocutors of the communicative act.

This comparative analysis located within Translation studies from a CDA viewpoint can provide a broader analytical angle for translation students helping them to recognize texts in connection with all kinds of textual and extra textual constrains such as ideology, power relations, and cultural and historical backgrounds. Indeed, this enquiry was an attempt to emphasize that the underlying ideological filter, most often as an invisible hand, makes every text unbiased or innocent let alone texts having politicized language. Therefore, translators, as any other language users who actively participate in the process of creating meaning, need to be very aware of and conscious about every discursive strategy or choice, ranging from deletion and addition to syntactic and lexical variations, they might adopt during the process of producing the target text on the basis of the source text. In this view, the findings of the present paper and/or other CDA based research aim to contribute to a better understanding of politically slanted texts whose contents are more or less transparent, and accordingly to give translators a deeper insight towards subtle persuasive strategies which place readers in specific ideological positions.

\section{References}

Banhegyi, M. (2009). The translator's ideology and reproduction of superstructure. WoPaLP, vol.3, 28-56. Bassnett, S.; Lefevere A. (1990) Translation, History and Culture. Casell, London. 
Bassnet,S. ; Schaffner,C. (eds). (2010). Political Discourse, Media and Translation. Cambridge Scholars Publishing: Newcastle upon Tyne.

Chilton, P.; Schäffner, C. (2002) Politics as Text and Talk. John Benjamins.

Fairclough, N. (1989) Language and Power. Longman, UK.

Fairclough, N. (1999) Critical Discourse Analysis: The Critical Study of Language. United Kingdom: Longman.

Fairclough, N. (200I) New Labor, New Language? Routledge, London and New York.

Fairclough, N. (2003) Analysing Discourse. Textual analysis for social research. Routledge, London and New York.

Fairclough, N. (2006) Semiosis, ideology and mediation. In Lassen, I.; Strunck J.; Vestergaard T. Mediating Ideology in Text and Image. Ten Critical Studies, 19-37. John Benjamins Publishing Company, Amsterdam/Philadelphia.

Halliday, M.A.K. (1978) Language as social semiotic. The social interpretation of language and meaning. Eward Arnold Publishers, London.

Halliday, M. A. K. \& Hasan, R. (1976). Cohesion in English. London: Longman.

Halliday, M. A. K. (1985/I994). An introduction to functional grammar. London: Edward Arnold.

Hatim, B.; Mason, I. (1997) The Translator as Communicator. Routledge, London and New York.

Hodge, B., and Kress, G. (2nd ed.) (1993). Language as ideology. Routledge: London and New York.

Lefever,A (ed.). (2002). Translation, history, culture. London: Routledge.

Munday, J. (2007a) Translation Studies. Theories and Applications. Routledge, London and New York.

Munday, J. (2007b) Translation and Ideology. A Textual Approach, I95-2I9. In Munday, J.; Cunico, S. Special Issue. The Translator. Translation and Ideology. Encounters and Clashes. Volume 13, Number 2. St. Jerome Publishing, Manchester, UK.

Nahrkhalaji,S. (2006). Translation: Ideology and power in political discourse. Retrieved from:http://www.ils.uw.edu.pl/PL2007/pliki/II8I989324Saeedeh\%20Shafiee\%20Nahrkhalaji.pdf

Schäffner, C. (1997) Strategies of Translating Political Texts, I 19-I45. In Trosborg, A. (ed.) Text Typology and Translation. John Benjamins Publishing Company, Amsterdam/Philadelphia.

Schäffner, C. (2002) The Role of Discourse Analysis for Translation and in Translation Training. Multilingual Matters Ltd., UK.

Schäffner, C. (2003) Third Ways and New Centres. Ideological Unity or Difference? In Pérez C. M. Apropos Ideology. Translation Studies on Ideology - Ideologies in Translation Studies, 23-43. St. Jerome Publishing, Manchester, UK and Northampton, MA.

Schäffner, C. (2004) Political Discourse Analysis from the point of view of Translation Studies, I I7-I50. In Journal of Language and Politics 3:I. John Benjamins Publishing Company, UK.

Schjoldager, Anne. 2008. Understanding Translation. Academica, Århus.

Trosborg, A. (ed.) (1997) Text Typology and Translation. John Benjamin's Publishing Company, Amsterdam/Philadelphia.

Tymocko, M. (2003) Ideology and the Position of the Translator. In What Sense is a Translator "In Between"? In Pérez C. M. Apropos Ideology. Translation Studies on Ideology - Ideologies in Translation Studies, I8I203. St. Jerome Publishing, Manchester, UK and Northampton, MA.

Valdeon, A., R. (2007) Ideological Independence or Negative Mediation: BBC Mundo and CNN en Español's Reporting of Madrid's Terrorist Attacks. In Carr, S.M. Translating and Interpreting Conflict, 99-I I9. Rodopi, Amsterdam/New York.

Van Dijk, A.T. (1997a) Discourse as Structure and Process. Discourse Studies: A Multidisciplinary Introduction. Volume I. SAGE Publications, London.

Van Dijk, T. (I997b) Political Discourse and Racism, in Riggins, H., S. (ed.), The Language and Politics of Exclusion. USA: SAGE Publications.

Van Dijk, T. (200I) Multidisciplinary CDA. In Wodak, R.; Meyer, M. Methods of Critical Discourse Analysis. SAGE Publications, Great Britain.

Wodak, R. (ed.) (I989) Language, Power and Ideology. John Benjamins Publishing Company, Amsterdam/Philadelphia.

Wodak, R.; Meyer, M. (200I): Methods of Critical Discourse Analysis. Great Britain: SAGE Publications. 
